\title{
Sulfonation, an underexploited area: from skeletal development to infectious diseases and cancer
}

\author{
Ada W.Y. Leung ${ }^{1,2}$, Ian Backstrom ${ }^{1}$ and Marcel B. Bally ${ }^{1,2,3,4}$ \\ ${ }^{1}$ Experimental Therapeutics, BC Cancer Research Centre, Vancouver, BC, Canada \\ ${ }^{2}$ Department of Pathology and Laboratory Medicine, University of British Columbia, Vancouver, BC, Canada \\ ${ }^{3}$ Faculty of Pharmaceutical Sciences, University of British Columbia, Vancouver, BC, Canada \\ ${ }^{4}$ Centre for Drug Research and Development, Vancouver, BC, Canada \\ Correspondence to: Ada W.Y. Leung, email: aleung@bccrc.ca \\ Keywords: sulfonation, PAPSS, sulfotransferases, heparan sulfate, tyrosine sulfation \\ Received: April 01,2016 Accepted: June 06, $2016 \quad$ Published: June 14, 2016
}

\section{ABSTRACT}

Sulfonation is one of the most abundant cellular reactions modifying a wide range of xenobiotics as well as endogenous molecules which regulate important biological processes including blood clotting, formation of connective tissues, and functionality of secreted proteins, hormones, and signaling molecules. Sulfonation is ubiquitous in all tissues and widespread in nature (plants, animals, and microorganisms). Although sulfoconjugates were discovered over a century ago when, in 1875, Baumann isolated phenyl sulfate in the urine of a patient given phenol as an antiseptic, the significance of sulfonation and its roles in human diseases have been underappreciated until recent years. Here, we provide a current overview of the significance of sulfonation reactions in a variety of biological functions and medical conditions (with emphasis on cancer). We also discuss research areas that warrant further attention if we are to fully understand how deficiencies in sulfonation could impact human health which, in turn, could help define treatments to effect improvements in health.

\section{BACKGROUND}

Our research team recently completed a genomewide siRNA screen to identify genes that, when silenced, would significantly enhance the cytotoxic effects of cisplatin when added at a sub-lethal dose [1,2]. This screen revealed a gene that when silenced increased the activity of platinum-based cytotoxic drugs (e.g. cisplatin, carboplatin, and oxaliplatin) as well as radiation and topoisomerase I inhibitors (e.g. irinotecan and topotecan) but not topoisomerase II inhibitors (e.g. doxorubicin). The gene encodes for 3'-phospoadenosine 5'-phosphosulfate (PAPS) synthase 1 (PAPSS1), a dual function enzyme comprising an ATP sulfurylase and a kinase domain. PAPSS1 functions sequentially to synthesize the biologically active form of sulfate (PAPS); the substrate used for sulfonation reactions in cells. PAPSS1 inhibition in combination with low-dose $\left(\mathrm{IC}_{10}\right)$ cisplatin resulted in increased DNA damage, apoptosis and G1/S cell cycle arrest. At the $\mathrm{IC}_{10}$ of cisplatin (i.e. the dose of cisplatin that would cause $10 \%$ cell death), PAPSS 1 inhibition reduced long-term viability of some cancer cells by $99 \%$ compared to non-targeting controls. These results suggest that sulfonation reactions are important for cancer cell survival. when attempting to understand what the role of PAPSS1 is in cancer we recognized a dearth of information. This review was undertaken to gain a better understanding of how sulfonation influences disease development and progression, with a particular focus on cancer.

\section{EVOLUTION OF SULFONATION}

Sulfonation plays an essential role in the biotransformation of endogenous compounds such as hormones and neurotransmitters as well as xenobiotics. Sulfonation reactions, catalyzed by sulfotransferases, involve the transfer of a sulfonate group (SO3-) from the obligate sulfate donor 3'-phoasphoadenosine-5'phosphosulfate (PAPS) to a hydroxyl or an amino 
group [3-5]. In humans, PAPS is the biologically active form of sulfate; biosynthesized by the enzyme 3'-phosphoadenosine-5'-phosphosulfate synthase (PAPSS) [4]. The synthesis of PAPS involves two reactions: inorganic sulfate is first converted to adenosine5'-phosphosulfate (APS) by ATP sulfurylase (EC 2.7.7.4) and this intermediate molecule is then phosphorylated by the APS kinase (EC 2.7.1.25) to form PAPS [6-8] (Figure 2 ). In prokaryotes, fungi, and plants, synthesis of PAPS is performed by two separate enzymes [9-13]. In animals, however, the ATP sulfurylase and the APS kinase are encoded by the same gene and translated into a single polypeptide which forms the dual-function enzyme PAPSS $[6,14]$. Both APS and PAPS are activated sulfuryl donors that possess a phosphor-sulfate anhydride bond [14] Phototrophic bacteria, algae, and some plants are known to utilize APS for the synthesis of the sulfur-containing amino acids cysteine and methionine via the assimilatory sulfate reduction pathway while chemotrophic bacteria, fungi, and some higher plants use PAPS [14-16]. The specificity for APS or PAPS is dependent on the presence of an iron-sulfur cluster in the sulfate-reducing enzymes of the organism [16]. Interestingly, these sulfate reduction pathways are not present in humans and other animals, meaning that methionine is an essential amino acid that can only be obtained through dietary sources $[14,16]$. PAPS in animals is used for a variety of sulfonation reactions (summarized in Figure 3) including the biotransformation of endo- and xeno-biotics, as described below. Hence, PAPSS has evolved structurally and functionally from prokaryotes to multi-cellular eukaryotes.

In humans, PAPSS exists in two isoforms: PAPSS1 and PAPSS2 [17]. While both isoforms are expressed ubiquitously, they differ in cellular localization and tissue distribution. PAPSS1 is localized to the nucleus while PAPSS2 is found primarily in the cytoplasm [18, 19]. PAPSS1 is required for the re-localization of PAPSS2 from the cytoplasm to the nucleus for additional PAPS production [19]. In terms of tissue distribution, PAPSS1 is the predominantly expressed isoform in brain and skin while PAPSS2 is most expressed in the liver, cartilage, and adrenal glands [14]. Relative distribution of the two isoforms varies in other tissues [14]. Deficiencies in the two isoforms are associated with different medical conditions as discussed below [20]. Altogether, these findings support that while both PAPSS1 and PAPSS2 catalyze the production of the obligate sulfonate donor PAPS, the two isoforms have non-redundant functions.

\section{SULFOTRANSFERASES XENOBIOTIC METABOLISM}

Sulfonation is most commonly known to be

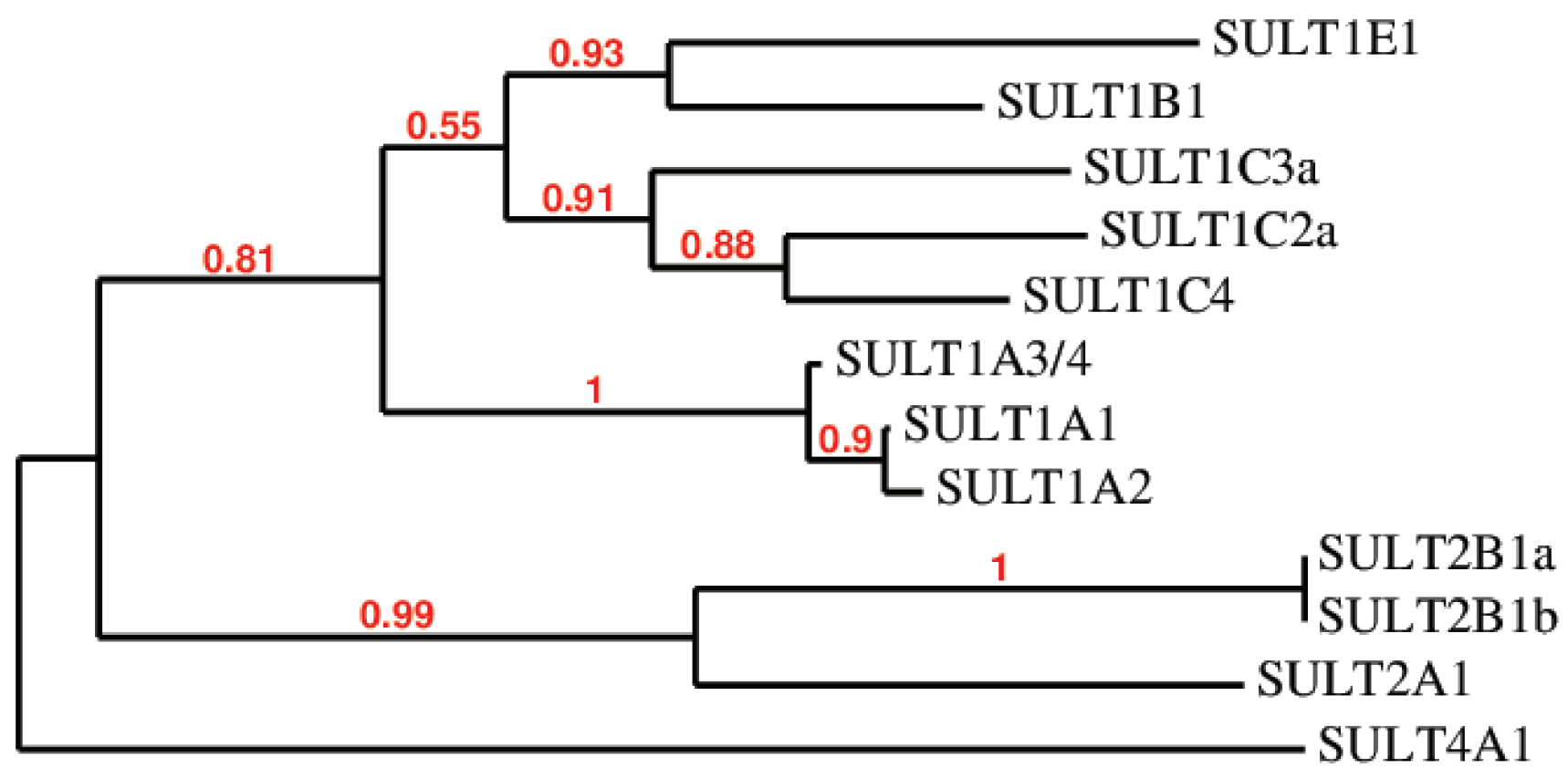

\section{5}

Figure 1: Amino acid sequence clustering of existing human SULTs. Amino acid sequences were retrieved from the NCBI Protein database and phylogenetic analysis was performed using MABL. The branch support values are provided in red. 
associated with the metabolism of xenobiotics that inactivate drugs such as acetaminophen by increasing their water solubility for excretion and decreasing their membrane permeability and biological activity through the addition of a charged moiety [5]. This modification is also partially responsible for drug resistance to chemotherapy in cancer treatments [21]. While PAPSS1 and PAPSS2 are responsible for the bioactivation of sulfate, sulfoconjugation reactions are catalyzed by enzymes known as sulfotransferases [4, 5]. Sulfotransferases are mainly divided into two groups: they are either cytosolic or membrane-bound [5, 22]. Cytosolic sulfotransferases constitute the superfamily of enzymes known as SULTs which are involved in the sulfonation of xenobiotics and small endogenous compounds such as neurotransmitters and hormones. The membrane-bound sulfotransferases are found in the Golgi apparatus and are responsible for posttranslational sulfonation of endogenous macromolecules such as proteins, lipids, and glycosaminoglycans [2224]. Currently, 12 SULT isoforms have been identified and detected in human tissues $[25,26]$. The Phylogenetic analysis of these isoforms was performed using MABL [27-33] and is shown based on amino sequence similarity in Figure 1. The chromosomal localization and tissue distribution of these isoforms have been described by Tibbs et al. in a recent review article [26]. Additional isoforms and splice variants have been predicted by other groups but are yet to be detected in human tissues at the protein level $[26,34,35]$. Generally, SULTs are grouped into four different families (SULT1, 2, 4, and $6)$ and they differ in their substrate specificity and tissue distribution $[4,25,36]$. SULTs are expressed at high levels during fetal development in humans [37]. In fact, some isoforms are only or primarily expressed during the prenatal period. The localization, expression levels, and the substrates (endogenous and foreign) of each SULT isoform characterized thus far are described in several comprehensive reviews [5, 37, 38]. A recent review by Coughtrie describes the function and organization of the different human SULT families [39]. SULT1 enzymes catalyze the sulfonation of catechnolamines and many other compounds [39]. SULT1A1 and SULT1B1 are the primary enzymes involved in the metabolism of xenobiotics in humans, making up nearly $70 \%$ of hepatic sulfotransferases. SULT1A1 is considered the major SULT isoform in human tissues as it is highly expressed in the liver and the gastrointestinal tract, conjugating small phenolic compounds such as estrogens, phytoestrogens, and minoxidil [40]. There are three isoforms within the SULT1A subfamily which differ in substrate specificity and thermostability despite sharing $>90 \%$ sequence identity [41]. SULT2 enzymes are selective for steroids such as cholesterol and bile acids [5, 25, 42, 43]. The physiological functions of SULT4 and SULT6 are poorly

\section{Step 1}

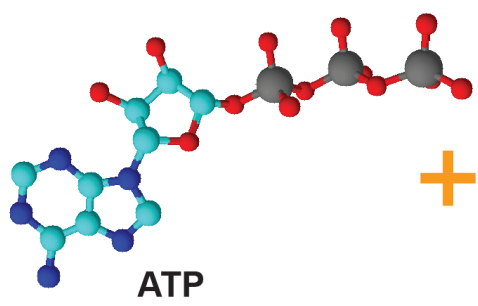

ATP
$\mathrm{SO}_{4}{ }^{2-}$

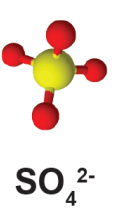

ATP Sulfurylase

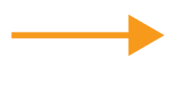

\section{Step 2}
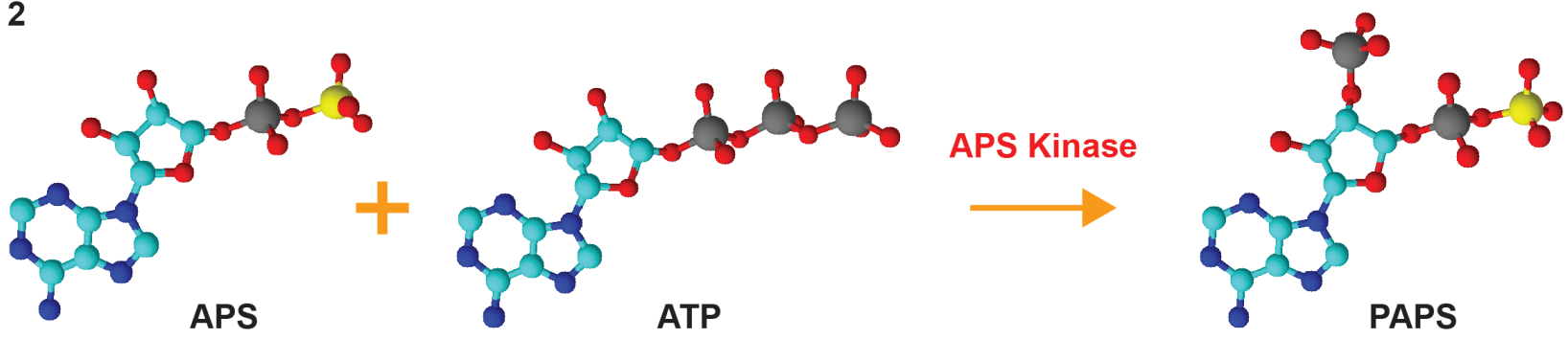

Figure 2: Bioactivation of inorganic sulfate. Inorganic sulfate is converted to the biologically active form PAPS (3'-phosphoadenosine 5'-phosphosulfate) by the dual-function enzyme PAPSS. Inorganic sulfate is first converted to adenosine 5'-phosphosulfate (APS) by ATP sulfurylase. The intermediate molecule APS is subsequently phosphorylated via the APS kinase domain of PAPSS to form PAPS. The structures were drawn using ChemSketch and are color-coded as follows: red $=$ oxygen, cyan $=$ carbon, blue $=$ nitrogen, yellow $=$ sulfur, grey $=$ phosphorous. 
understood $[25,42]$.

Sulfonation has been recognized as a high-affinity, low-capacity conjugation system that relies heavily on the availability of PAPS, which is dependent on its synthesis, use, and degradation [7, 26]. PAPS levels vary in different tissues and are believed to limit the sulfonation capacity of various cell types [26]. Although each SULT isoform is known to have different tissue distribution and affinity for specific classes of substrates, it is also believed that PAPS concentrations are important in regulating substrate selectivity. Interesting studies by Cook et al. suggest that nucleotide binding triggers a gating mechanism that affects substrate selectivity [44]. Following nucleotide binding, there is a conformational change in the protein that limits substrate access to the catalytic domain. The authors showed in silico predictions of how saturating concentrations of PAPS could substantially decrease the affinity of SULT2A1 for large substrates. Whether these gating mechanisms apply to all human SULTs and the exact mechanism of" how substrate selectivity is regulated in each isoform remain"s" to be investigated.

In most cases, sulfoconjugation is associated with detoxification. Some compounds, however, are bioactivated upon sulfonation by sulfotransferases [5]. Sulfonation could result in the generation of reactive electrophiles that can bind DNA, eliciting a mutagenic

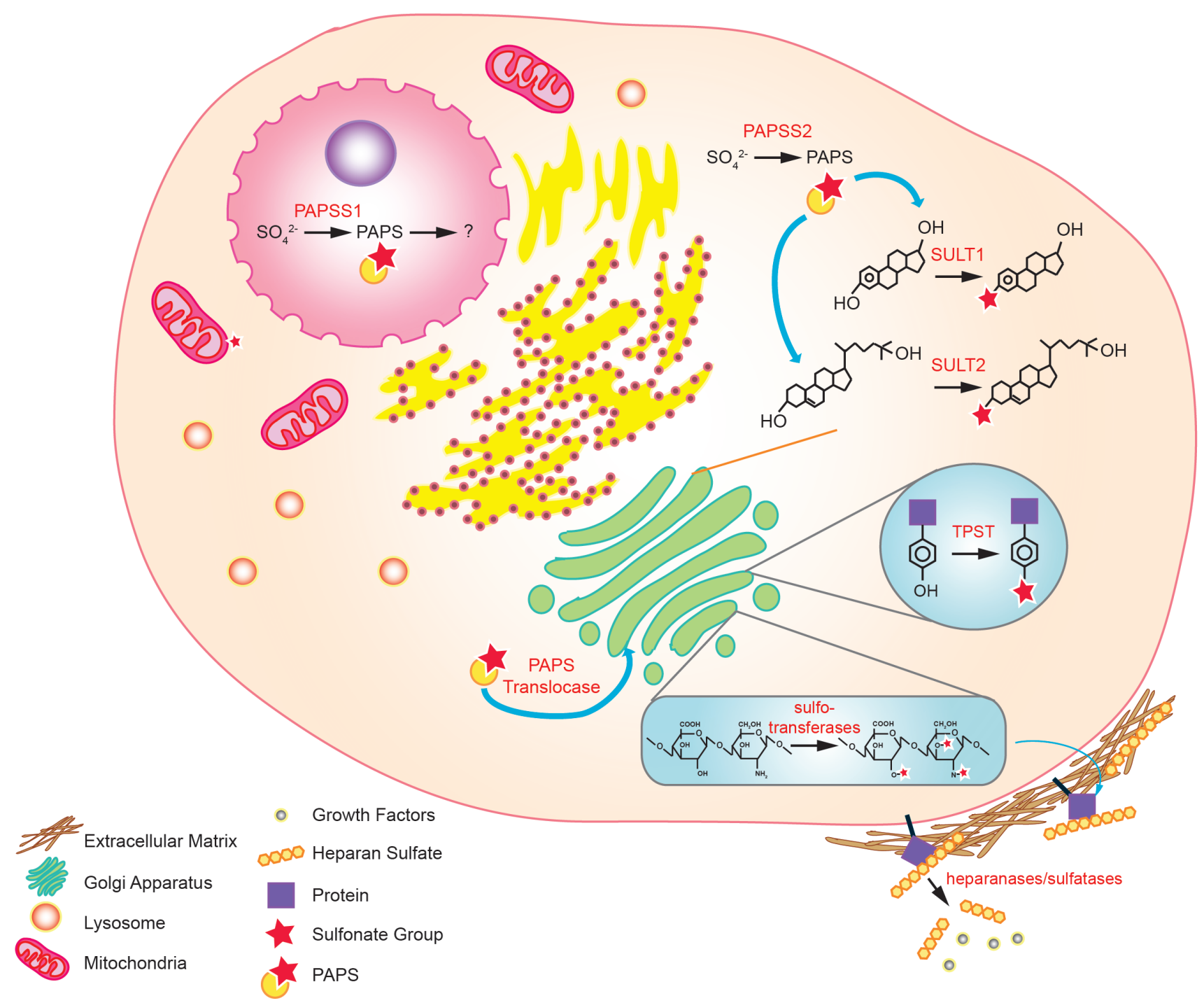

Figure 3: Sulfonation reactions in human cells. In the nucleus, conversion of inorganic sulfate to PAPS is catalyzed by PAPSS1. In the cytoplasm, the same reaction is catalyzed by PAPSS2. The PAPS produced in the cytoplasm is used by cytosolic sulfotransferases to biotransform endo- and xeno-biotics. Cytosolic PAPS can also be transported to the golgi apparatus via the PAPS translocase, where tyrosine sulfation of proteins and sulfo-conjugation of polysaccharides occur. Sulfonated molecules such as heparan sulfates (HSs) may be secreted to the extracellular matrix or attached to cell surface proteins. Some of the HS may sequester growth factors that are released upon cleavage by heparanases and sulfatases. 
or even carcinogenic response $[23,36]$. Based on screens conducted using recombinant bacteria, mammalian cell lines, and cell-free systems, about 100 compounds were identified to be genotoxic upon sulfonation by SULTs [36, 45]. Many studies have also shown that brachymorphic mice, which suffer from a PAPSS2 genetic defect (like patients with Pakistani spondyloepimetaphyseal dysplasia), are more resistant to tumorigenesis when exposed to procarcinogens known to be activated via sulfonation [46]. It is also possible that sulfo-conjugation may enhance the therapeutic activity of certain drugs. Minoxidil, an anti-hypertensive and hair growthstimulating drug, is one such example where the sulfate metabolite is responsible for its biological activity [23, 47, 48].

\section{TYROSINE SULFONATION}

Aside from biotransformation of xenobiotics, sulfonation is also the most abundant post-translational modification of tyrosine residues [49]. About $1 \%$ of the tyrosines are sulfonated [50]. While sulfonation is the appropriate term to describe the transfer of sulfonate groups $\left(\mathrm{SO}_{3}\right)$, the same reaction has been described widely as sulfation in the literature, particularly when discussing proteins and proteoglycans that have been sulfonated (ie. tyrosine-sulfated proteins and heparan sulfates). Here, we will use the term "sulfates" when referring to sulfonated tyrosine residues and glycosaminoglycans as these structures are commonly referred to as sulfates in the literature.

Currently, there is no evidence of protein tyrosine sulfonation (PTS) in yeasts and in prokaryotes, suggesting that PTS first appeared in multicellular eurkaryotes [50, 51]. Tyrosylprotein sulfotransferase (TPST), the enzyme responsible for PTS, resides in the trans Golgi, and PAPS, the obligate substrate for the reaction, is transported from the cytoplasm to the Golgi via a PAPS translocase [50, 52-54]. PTS has a multitude of biological functions, many of which are still being characterized [22]. PTS can be important for the biological activity of certain neuropeptides. For instance, sulfonated cholescystokinin, a hormone important for the secretion of digestive enzymes, is at least 200 times more active than its unsulfonated counterpart [50]. Translated proteins can also be modified by PTS to diversify their functionality. As an example, gastrin normally regulates the secretion of gastric acid. When sulfonated by PTS, gastrin can also function as a pancreatic secretagog [55]. The extent of proteolytic processing of gastrin is also associated with PTS, suggesting that PTS can regulate proteolytic cleavage [50].

With increasing interests in the biological roles of PTS, studies have started to focus on the importance of PTS in mediating the immune response [51, 56-58]. At sites of inflammation, adhesion of leukocytes to activated endothelium requires interactions between $\mathrm{P}$-selectin on the endothelial cells and P-selectin glycoprotein ligand (PSGL)-1 on leukocytes. PTS is necessary at the tyrosine residues of PSGL-1 to facilitate this interaction [51, 5658]. The presence of sulfonated tyrosine residues is also proving essential for proper blood clotting in response to vessel injuries as well as binding of chemokines to the chemokine receptors CCR5 and CXCR4 [51, 59].

\section{HEPARAN SULFATES}

Heparan sulfate (HS) is a polysaccharide that is produced by virtually all cells [60]. HSs are often attached to proteins forming heparin sulfate proteoglycans (HSPGs) at the cell surface or in the extracellular matrix (ECM) [61]. Its basic structure consists of alternating hexuronic acid (D-glucuronic acid (GlcA) or L-iduronic acid (IdoA)) and D-glucosamine (GlcN) units [62]. The carbohydrate backbone is constructed as a polymer and then modified by a series of enzymes including glycosyltransferases, O-sulfotransferases, and an epimerase in the Golgi apparatus to form the final structure [60, 61]. HSPGs are known to be structurally diverse, with great variability in their chain lengths and sulfation patterns. This gives rise to an immense number of HS species that can bind different proteins such as chemokines, growth factors, and enzymes and serve a variety of functions including immobilization, protection from proteolytic cleavage, as well as roles in embryonic development, angiogenesis, cell adhesion, blood coagulation, and lipid metabolism [61-64]. The biosynthesis and roles of HS can be further explored in depth in excellent previously published review articles $[60,61,65-68]$.

\section{SULFONATION IN THE CONTEXT OF DISEASES AND CANCER}

\section{Genetic defects and deregulation in the sulfonation pathway}

Genetic defects in the sulfonation pathway can have a wide range of effects. For instance, mutations in the diastrophic dysplasia sulfate transporter are associated with a lethal autosomal recessive disorder called achondrogenesis type 1B. This disorder is characterized by short limbs and pulmonary hypoplasia due to abnormal skeletal development [69-71]. Loss-of-function mutations in PAPSS2 are associated with a type of dwarfism called brachyolmia type 4, a non-lethal genetic disorder that affects the spine [72]. Some, PAPSS2 mutations can lead to brachyolmia or more severe skeletal disorders such as spondyloepimetaphyseal dysplasia Pakisani type, characterized by a number of abnormalities in the skeleton and the cartilage between long bones resulting in short stature and bowed legs. [72]. 
In the context of tyrosine sulfation, there are two known human isoforms of TPST [73]. In mice, double knockouts of the two TPSTs result in post-natal pulmonary failure and death as the lungs fail to expand [74]. Loss of TPST-2 activity causes hypothyroidism in mice, suggesting that the two isoforms have nonredundant substrate specificities and that tyrosine sulfation is necessary for normal pulmonary and thyroid gland functions $[74,75]$.

As mentioned above, PTS is important for inflammatory response. Specifically, in conditions associated with airway inflammation such as asthma and chronic obstructive pulmonary disease (COPD), PTS is prevalent [76]. It is known that binding of chemokines to chemokine receptors is essential in the regulation of leukocyte trafficking $[77,78]$. Studies have demonstrated that the affinity of chemokine receptors to different chemokines is dependent on the sulfonation states of the tyrosine residues on the chemokine receptors [77]. In COPD patients, PSGL-1 is up-regulated on the surface of all leukocyte populations, where PTS plays a critical role in enhancing the interaction between immune cells and the bronchial endothelium [78].

\section{Roles of sulfonation in viral infections}

The cellular sulfonation pathway is also known to be important for viral infections $[79,80]$. HS is ubiquitous on the surfaces of cells and the highly sulfonated nature of HS provides ample negative charges that could interact with the positively charged viral proteins, promoting initial interactions between viruses and host cells [80]. In some cases, the interaction is much more specific. For instance, herpes simplex virus type 1 (HSV-1) binds to $\mathrm{HSs}$ on target cells via envelope glycoproteins $\mathrm{gB}$ and $\mathrm{gC}$, but viral entry is mediated through the interaction between viral glycoprotein D and a specific 3-O-sulfonated HS [8083].

To date, HSs are known to be involved in at least 16 different types of viral infections, including hepatitis $\mathrm{C}$, human papillomavirus (HPV) and human immunodeficiency virus (HIV) [80]. In the case of HIV, the sulfonation pathway appears to be critical in multiple steps of viral infection. It has been established the binding of HIV involves an interaction between the envelope glycoprotein gp120 and syndecans, which are transmembrane HSPGs found on the cell surfaces of T-cells and macrophages [80, 84]. While HIV-1 only infects CD4+ cells, the attachment of the virus to the HSs of a non-permissive cell actually aids the virus in retaining its infectivity for a longer period than it would otherwise as a free virus [85]. This suggests that cells lacking CD4 expression may provide a reservoir for any bound HIV-1 [85].

Successful infection of HIV-1 virus requires expression of CD4 as well as the presence of specific co-receptors on the host cells. The chemokine receptor CCR5 is a major co-receptor that facilitates the entry of HIV-1 into target cells [59]. CXCR4 is another chemokine receptor that is commonly used by HIV-1 viruses as the infection progresses [86]. Based on studies completed by Farzan et al., both CCR 5 and CXCR4 are sulfonated [59]. Specifically, when the tyrosine residues at the $\mathrm{N}$ terminus of CCR5 are mutated to phenylalanine and therefore are not sulfonated, there is a marked decrease in the binding of CCR5 with MIP- $1 \alpha$, MIP-1 $\beta$, and gp120/CD4 complexes, significantly reducing the ability of HIV-1 to enter their target cells [59]. It has also been recently established that PAPSS1 plays a critical role in gene expression from the long terminal repeat promoter following provirus establishment [79]. In this example, the transcriptional activity may be influenced by sulfonation in an epigenetic manner [79]. Although the mechanism is not fully understood, it is clear from the work of Bruce et al. that sulfonation in the nucleus is required for proper expression of LTR-driven genes which is needed for viral replication [79]. Finally, HIV-1-infected cells are known to release a protein called Tat (transactivator protein), the causative agent of AIDS (acquired immune deficiency syndrome), which is known to damage tissues and cells and is associated with neurotoxicity and increased risks of developing cancer $[80,87,88]$. Tat can also cause nonpermissive cells to become susceptible to HIV infections [80]. The internalization of Tat into cells is facilitated, again, by HSs $[80,88]$. As summarized here using $\mathrm{HIV}$ as an example, sulfonation plays essential roles in viruses' ability to infect and complete their life cycles in humans. Also the structural diversity of HS is immense and extensive studies in this area are therefore necessary to fully understand how specific HSs aid in the infections of different viruses.

\section{Sulfonation and cancer}

While phosphorylation is extensively studied in cancer development and treatments, sulfonation has been largely overlooked in the context of oncology [89]. It is only in recent years that there is a growing body of evidence that individual differences in various genes of the sulfonation pathway may contribute to carcinogenesis and patient survival. For instance, polymorphisms in SULT1E1, a sulfotransferase that is involved in estrogen metabolism, are correlated with the survival of patients with estrogen-dependent cancers. Studies conducted by Hirata et al. and Rebbeck et al. demonstrated that polymorphisms in SULT1E1 are associated with greater endometrial cancer risks $[90,91]$. In estrogen receptor (ER) positive breast cancers, tumorigenesis and disease progression rely on the presence of estrogen [92]. SULT1E1 is known to be overexpressed (relative to breast cancer cells) in normal human mammary epithelial cells [93]. In a recent study, Xu et al. demonstrated 
that overexpression of SULT1E1 and PAPSS1 can block estrogen-stimulated cell proliferation in MCF-7 breast cancer cells, while promoting apoptosis through upregulation of the pro-apoptotic gene bax [94]. It is important to note that the role of estrogen sulfonation in cancer patients could be complicated as some SULT isoforms have overlapping substrate specificity and need to be considered. For instance, SULT1A1 catalyzes the sulfonation of a variety of small phenolic compounds including estrogen and is known to be associated with breast cancer risks [95, 96]. Tamoxifen, an agent that is commonly used to treat breast cancer, is a prodrug that is metabolized by SULT1A1 to its activated metabolite 4-hydroxytamoxifen (4-OH TAM) in the liver. Polymorphisms in SULT1A1 are known to exist and one particular variant SULT1A1*2 (where Arg at codon 213 is substituted with His) has been seen in some breast cancer patients [97]. This enzyme has significantly lower enzymatic activity and thermostability than the wild-type enzyme [97]. While the investigators expected SULT1A1*2 to correlate with improved survival due to reduced sulfonation of 4-OH TAM they surprisingly found that the variant allele was associated with poor survival in patients who were treated with tamoxifen [97]. This observation was supported by another study conducted by Wegman et al [98]. It was suggested that the sulfated 4-OH TAM metabolite actually serves as a potent inducer of apoptosis, thus improving the survival of individuals with the SULT1A1 genotype that has higher enzymatic activity [99]. In another study, women bearing benign and malignant gynecological tumors were found to have a higher frequency of the common allele of SULT1A1, suggesting that there was an increase in endometrial cancer risk with greater SULT1A1 activity [100]. However, other studies have found either no or negative correlation between SULT1A1*2 and endometrial cancer risks. Clearly there is a need for further investigations [101-103].

Polymorphisms in SULT1A1 have also been studied in patients with estrogen-independent cancers. Several studies in lung cancer have demonstrated that the variant SULT1A1*2 allele is associated with increased risks of lung cancer, especially for smokers [104-106]. Interestingly, contrasting results were found in bladder cancer. Women and never smokers with the His (213) allele were found to have reduced risks of bladder cancer [107]. The variant allele even appears to provide some protective effects for smokers against bladder cancer $[107,108]$. The same polymorphism is associated with significantly greater risks of upper urinary tract urothelial cell carcinoma, head and neck cancer, gastric cancer, and colorectal cancer, particularly in smokers and consumers of alcohol and red meat [109-112]. These findings suggest that SULT1A1 activity plays roles in carcinogenesis in a tissue-specific manner.

Aside from SULTs, heparan sulfate proteoglycans and chondroitin sulfate proteoglycans (CSPGs) have also been shown to be associated with cancer. Chondroitin sulfates (CS) are sulfonated glycosaminoglycans complexed with core proteins to form CSPGs that reside at the cell surface and extracellular matrix [113]. CSs are synthesized during embryonic development as polysaccharides of alternating D-glucuronic acid and D-Nacetyl-galactosamine units which are further modified via sulfonation $[113,114]$. CSPGs are highly expressed in the vessels of brain tumors and the stroma of various types of cancer including melanoma, prostate, breast, testicular, colon, pancreatic, and gastric cancers and are known to play important roles in tumor growth and invasion [113-118]. The anionic nature of CS chains facilitates interactions between cells through binding of ligands and receptors that result in activation of signaling pathways that promote tumor growth and metastasis [113, $119,120]$. In head and neck cancer, patients appear to excrete chondroitin sulfates in their urine, which could be useful for diagnostic purposes [114].Recently, Poh et al. have synthesized a library of CS disaccharides to evaluate the effects of different sulfonation patterns on breast cancer cell viability [121]. Their results suggest that the presence of specific sulfonation patterns could lead to growth inhibition in a triple negative breast cancer cell line. A review written by Asimakopoulou et al. describes additional biological roles played by CS in different types of malignancies as well as an overview of several modified CSs that have been tested as targeting and therapeutic agents [113].

Similar to CSPGs, the abundance and diversity of HSPGs at normal and tumor cell surfaces and in the extracellular matrix affect cancer biology by initiating transformation of normal cells, modulating tumor growth, and promoting metastasis [122]. For instance, Glypican-3 (GPC3) is a HSPG that negatively regulates cell proliferation and survival [123]. Several studies have shown that GPC3 expression is reduced in mesothelioma, breast cancer, and ovarian cancer cells [122-125]. In other studies, induction of the sulfatase SULF2 was found in breast cancer and lung cancer [126, 127]. Sulf-2 expression is associated with activation of the Wnt signaling pathway which promotes cell proliferation $[126,128]$. In contrast, suppression of Sulf-2 in cancer cells inhibited cell growth and even partially reversed transformation in vitro [126].

As mentioned earlier, different sulfonation patterns on HSPGs enable them to bind different molecules including growth factors. HSPGs therefore can sequester growth factors and release them upon degradation of their HS chains by heparanases or changes in sulfonation patterns by sulfatases, directly regulating cell proliferation [89, 122]. Vascular endothelial growth factor (VEGF) and fibroblast growth factors (FGF) are growth factors that are also released from HSPGs by endosulfatases and heparanases in the extracellular matrix [89, 129]. Pericellular HSPGs can facilitate the binding of VEGF 
and FGF with their corresponding receptors on endothelial cells and activate these signaling pathways that are central to the process of angiogenesis [130]. While HSPGs can sequester or release pro-angiogenic factors, other HSPGs can inhibit angiogenesis by binding the anti-angiogenic factor endostatin. The ultimate stimulation or inhibition of angiogenesis is therefore a fine balance between the concentrations and binding affinities of pro- and antiangiogenic factors, which are highly dependent on the HSPG profiles of cells in the tumor microenvironment $[122,130]$. As an example, Cole et al. have demonstrated that down-regulation of HS 6-O-sulfotransferases 1 and 2 leads to reduced 6-O-sulfonation, reduced endothelial cell signaling and angiogenesis, and significantly delays the growth of ovarian cancer tumours in vivo [131]. A recent study conducted by Mao et al. reveals the role of the heparan sulfate sulfotransferase 3-OST3A (HS3ST3A) in regulating tumour growth in breast cancer by controlling the tumour microenvironment [132]. Depending on the tumour subtype, 3-OST3A expression could induce onocgenic or tumour-suppressive effects and even affect therapeutic responses by regulating the activity of FGFs. A similar study was conducted by Kumar et al., investigating the role of heparan sulfate 3-O-sulfotransferase 2 (HS3ST2) on the invasiveness of highly and low invasive breast cancer cells [133]. While FGFs are more commonly known to be involved in cancer cell proliferation, Jung et al. has recently shown that PAPSS2 depletion leads to under-sulfonation of HSPGs, which in turn augments FGFR1 and Akt signaling, ultimately inducing premature cellular senescence, a tumour-suppressive mechanism that could lead to tumour clearance through an innate immune response [134].In terms of tumor metastasis, HSPGs, again, play opposing roles. Along with collagen and laminin, HSPGs construct a protective barrier through tight cell-cell and cell-ECM adhesions [135]. Heparanases and other enzymes released by tumor cells help to modify these barriers as needed for invasion and metastasis [136-139]. Therefore, in most cases, tumor cells with low levels of HSPGs are correlated with high metastatic potential [135]. Specifically, studies in recent years have demonstrated that the expression of a specific HSPG, syndecan-1, is associated with changes in tumor cell morphology. Syndecan-1 expression is negatively correlated with metastatic potential and poor prognosis in many different types of malignancies including mesothelioma, colon, lung, liver, breast, and head and neck cancer [135, 140-145]. The involvement of syndecan-1 in metastasis is explored in depth in a review written by Sanderson [135]. Since the interactions between tumour cells and the endothelium during metastasis are poorly understood, Martinez et al. conducted a study and demonstrated that cancer-associated glycosaminoglycans can serve as ligands for selectins in the endothelium and are recognized and bound based on sulfonation density and $\mathrm{pH}$ conditions [146]. These interactions help promote distant metastases.

While cell surface HSPGs are important for preventing tumor invasion, HSPGs in the ECM are involved in promoting metastasis. Extracellular HSPGs secreted by cells are known as perlecans while syndecans are cell surface HSPGs that could also be shed either into the ECM or into blood [135]. Studies have shown that suppression of perlecans decreases the invasiveness of metastatic melanoma and prostate cancer cells $[147,148]$. While the mechanism of action of perlecans is yet to be defined, it has been suggested that perlecans and other HSPGs in the ECM may bind chemokines and growth factors, establishing gradients that direct the motility of migrating tumor cells [135].

As described above, HSPGs form a physical barrier with collagen to prevent invasion. Soluble HSPGs could also promote tumor cell invasion by interfering with cell-cell interactions. Studies suggest that exogenous HSs allow non-invasive cells to become highly invasive in several rodent tumor and human leukemia cell lines $[149,150]$. Once tumor cells have escaped from their primary site into the vasculature, their cell surface HSPGs may aid in their motility as well as their extravasation out of circulation [135]. For this reason, intravenous administrations of different species of HSs and anti-HSPG antibodies were tested in an attempt to block HS function in the vasculature and ultimately inhibit metastases [151153].

In summary, tumor cells may secrete heparanases and other enzymes to degrade cell-surface HSPGs and ECM-bound HSPGs in the proximity to initiate the metastatic processes. Subsequently, cell surface HSPGs aid in migration, extravasation: promoting "seeding" at their metastatic sites. All of these steps involve a variety of HSPG species, enzymes, and signaling molecules that are dynamically regulated by the tumor cells. This suggests great opportunities for the development of therapeutics, targeting HSPGs including the use of modified HSPGs, antibodies, and heparin. Heparin, an anticoagulant, is structurally similar to HSPGs and has been found to be anti-metastatic in multiple animal models for undefined reasons. These strategies are discussed in detail in several review articles [122, 153-156]. While the connection between HSPGs and cancer is well-established, there is still much to learn because the role is complex, depending on the tissue type, tumor subtype, the presence of enzymes, growth factors, and other HSPGs, as well as the localization (cell-surface vs. ECM) and structural characteristics (sulfonation pattern) of each HSPG. It is also important to explore how the activity of PAPSS enzymes and the availability of PAPS, which are utilized in all sulfonation reactions, affect the structure and function of HSPGs. 


\section{SULFONATION IN THE NUCLEUS: THE UNCHARTED TERRITORY}

Sulfonation is known to be involved in a broad spectrum of biological processes in both healthy and diseased cells. As indicated above, most studies have focused on the importance of sulfonation in cell-cell or cell-ECM communications and the modification of endo- and xenobiotics. However, very little is known about the sulfonation pathway in the nucleus, the control center of the cell. As mentioned above, two isoforms of
PAPSS exist in humans, both of which contain a nuclear localisation signal (NLS) for translocation from the cytoplasm to the nucleus of the cell [19]. The NLS is more efficient in PAPSS1 and subcellular localization studies conducted by Besset et al. have shown that PAPSS1 localizes to the nucleus while PAPSS2 is predominantly found in the cytoplasm [18]. When co-expressed with PAPSS1, PAPSS2 is relocated to the nucleus [18]. Therefore, PAPSS2 may relocate to the nucleus when a greater demand for PAPS needs to be met in the nucleus. These data suggest that there is a critically important role
A

A2780-S

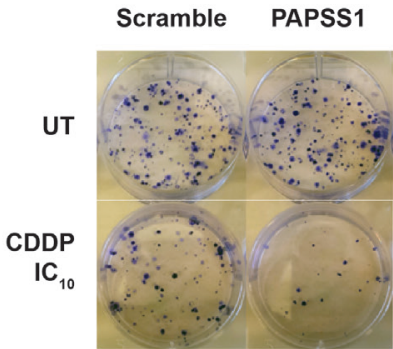

SKOV-3

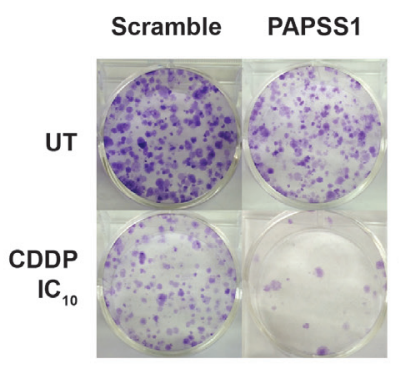

A549

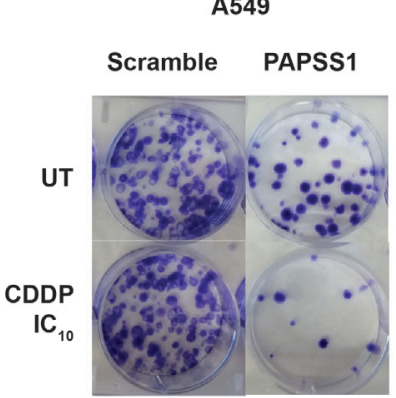

A2780-CP

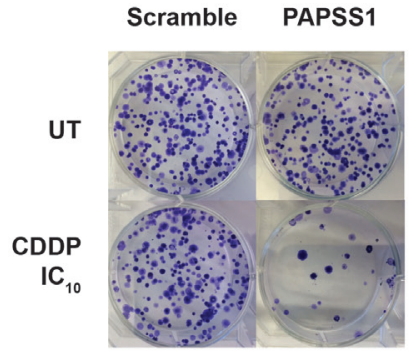

SKOV-3

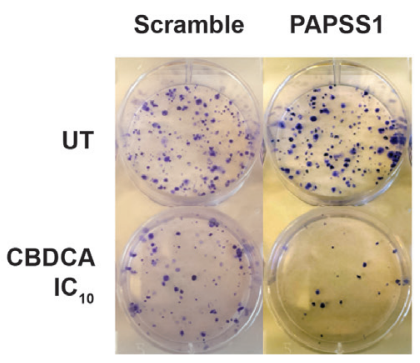

H460

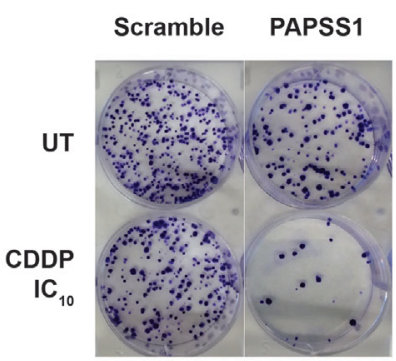

B

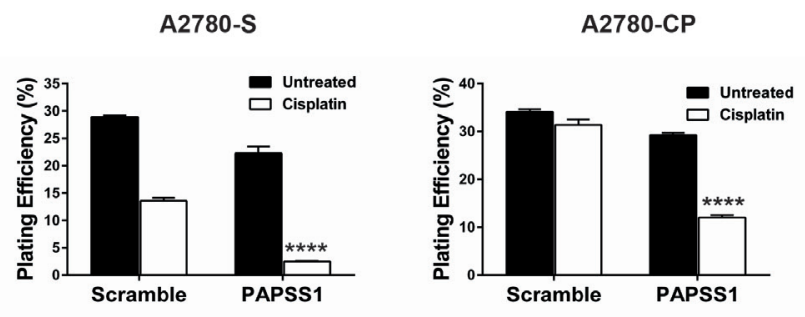

SKOV-3

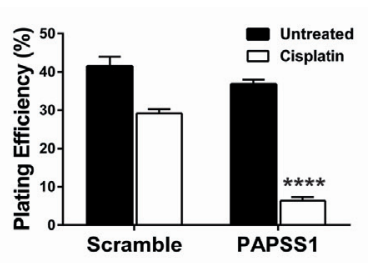

SKOV-3

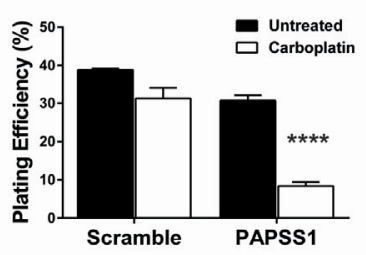

A549

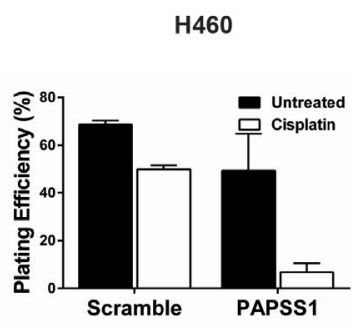

Figure 4: PAPSS1 knockdown sensitizes ovarian and lung cancer cells to platins. Cisplatin (CDDP) sensitive (A2780-S) and resistant (A2780-CP) A2780, SKOV-3, A549, and H460 were seeded in 6-well plates and transfected with a pool of three PAPSS1targeting or non-targeting siRNA duplexes the following day. The empirically determined IC10 of the corresponding platinum agent based on a $72 \mathrm{~h}$ cell viability assay was added to the cells 24 hours post-transfection $(0.112,1.24,0.98 \mu \mathrm{M}$ CDDP for A2780-S, - CP, and SKOV-3 respectively; $19.3 \mu \mathrm{M}$ carboplatin (CBDCA) for SKOV-3; 0.71 and $0.52 \mu \mathrm{M}$ CDDP for A549 and H460, respectively). At 24 hours posttreatment, the cells were harvested and re-seeded for colony formation. The cells were subsequently incubated for 14 days undisturbed, after which the colonies were fixed and stained with $0.5 \% \mathrm{w} / \mathrm{v}$ crystal violet in $6.25 \%$ glutaraldehyde and counted. The plating efficiency (PE) was calculated using the equation (\# colonies formed/\#cells seeded) $\times 100 \%$. Representative images of the treatment conditions are shown in A and the PE values are plotted in B. All data are shown as mean \pm SEM. Two-way ANOVA with Tukey adjustments for multiple tests comparison was used and the statistical significance of the sensitization effects of PAPSS1 knockdown is highlighted for each cell line $(* * * * p 0.0001$ for platin-treated scramble $v s$. PAPSS1-silenced cells). 
of the sulfonation pathway in the nucleus. The existence of a functional sulfonation pathway is further confirmed by studies completed by Bruce et al. where PAPSS1 was identified to be involved in suppressing transcriptional activities from the LTR promoter upon provirus establishment in the host cells [79].

In our laboratory, an siRNA screen led to PAPSS1 as a target that may potentiate non-small cell lung cancer (NSCLC) cells to cisplatin treatment [1]. Validation studies further demonstrated that PAPSS1 can be suppressed to enhance the therapeutic activity of a range of DNA damaging agents, including radiation, other platinumbased agents, as well as topoisomerase I inhibitors [1]. The sensitization effects were observed in both platinumsensitive and resistant cell lines via colony formation assays (Figure 4) [1,2].This sensitization was selective for cancer cells as strong inhibition of PAPSS1 at the protein level did not sensitize normal bronchial epithelial cells to cisplatin treatment [1]. Validation of PAPSS1 as a therapeutic target has been further demonstrated in multicellular tumor spheroid models as well as in zebrafish and rodent models (Leung et al., submitted manuscript). These results suggest that the sulfonation pathway plays an important role in the survival of cancer cells following exposure to chemotherapy.

According to the cBioPortal database, only approximately $7 \%$ of breast cancers and $2 \%$ of lung adenocarcinoma harbour PAPSS1 amplifications and mutations [1]. Currently, there is no database that can assess how PAPSS1 expression affects treatment response. A study conducted by Shih et al. has shown that single nucleotide polymorphisms in the ATP sulfurylase domain of PAPSS1 was correlated with poor survival in patients with familial or early onset hepatocellular carcinoma (HCC) [157]. The causal relationships between PAPSS1 and HCC survival has not been elucidated and the mechanism(s) by which PAPSS1 sensitizes NSCLC and ovarian cancer cells to DNA damage are yet to be defined. While our previous studies demonstrated increased accumulation of DNA damage when PAPSS1deficient NSCLC cells were treated with cisplatin and topotecan, further research is needed to fully understand the mechanism of action as there is a lack of knowledge of the roles of sulfonation in the nucleus of eukaryotic cells. Recent studies have shown that PAPSS1 can form a heterodimer with the evolutionarily older isoform PAPSS2 $[158,159]$. However, the function of this heterodimer and its potential role in regulating overall PAPS production is unclear. Therefore, although the PAPSS enzymes are starting to become recognized as potential contributors to cancer and other human diseases, research in the two enzymes that produce the substrate for all cellular sulfonation reactions is in its infancy and warrants further attention.

\section{CONCLUSIONS \\ AND \\ FUTURE PERSPECTIVES}

Sulfonation is a key post-translational modification process that affects a tremendous number of biological activities through cell-cell and cell-matrix communication. There is a great amount of research concerning the roles of glycosaminoglycans and proteglycans in diseases but it has been difficult to apply this knowledge to therapeutic applications because of the structural diversity and the tissue-specific nature of responses. There are growing interests in the roles of sulfotransferases in different types of malignancies; however, conflicting results suggest the need for greater sample sizes and more studies to understand how sulfotransferase activities affect cancer development, progression, and treatment responses in different organs. Protein tyrosine sulfonation is another area that is largely underexplored. Which proteins in the proteome are tyrosine sulfonated? Part of this challenge concerns development of reliable methods for measuring sulfonated tyrosines on proteins. Some groups have been trying to predict sites of PTS by developing software and algorithms while more and more tyrosine sulfonated proteins are being identified in recent years $[51,160]$. We are, however, still far from finding all tyrosine sulfonations and this, in turn, limits our ability to understand the role that tyrosine sulfonation plays in biology. Other questions that will need to be addressed in the future include: 1) How do cells alter HSPG expression on the cell surface? 2) How does the supply of PAPS affect the sulfonation efficiency of different sulfotransferases in different tissues? 3) Which processes require PAPS in the nucleus? From our perspective, focused on cancer, we believe that answering these questions will first require the recognition that sulfonated proteins and glycans in different cellular compartments and organs play important roles in cancer cell proliferation and survival.

Currently, a great amount of effort is focused on discovering inhibitors that target phosphorylated proteins to reduce signaling of hyper-activated pathways in cancer cells. There are, however, still many unexplored areas that could be of great importance in cancer treatment. Sulfonation is one where many correlations with tumorigenesis and patient survival have been recognized, but little is known about the mechanisms of action and casual relationships. The area is extremely broad and requires extensive research looking at the impact of sulfonation in various cellular compartments, tissue types, as well as its involvement in cancer cell mobility, invasion, and metastasis. Death from cancer is almost always attributed to metastasis [161] and there is a need to explore all potential strategies that may prevent or slow the development of metastasis. In this context, more research is needed to understand the role of PAPSS enzymes in cancer cell biology. 


\section{ACKNOWLEDGMENTS}

Dr. Marcel Bally acknowledges the Canadian Institutes of Health Research (CIHR) for their financial support (MOP 89948). Ada Leung thanks the CIHR and the University of British Columbia for their financial support through the Vanier Canada Graduate Scholarship and the Four-Year Doctoral Fellowship respectively. The authors also thank the Centre for Drug Research and Development for their financial support on PAPSS1 target validation as well as the Carraresi Foundation, B.C. Cancer Foundation, and VGH \& UBC Hospital Foundation for their financial support through OVCARE.

\section{CONFLICTS OF INTEREST}

The authors have no conflict of interest to disclose.

\section{REFERENCES}

1. Leung AW, Dragowska WH, Ricaurte D, Kwok B, Mathew V, Roosendaal J, Ahluwalia A, Warburton C, Laskin JJ, Stirling PC, Qadir MA and Bally MB. 3'-Phosphoadenosine 5'-phosphosulfate synthase 1 (PAPSS1) knockdown sensitizes non-small cell lung cancer cells to DNA damaging agents. Oncotarget. 2015; 6:17161-17177. doi: 10.18632/oncotarget.3635.

2. Leung AW, Hung SS, Backstrom I, Ricaurte D, Kwok B, Poon S, McKinney S, Segovia R, Rawji J, Qadir MA, Aparicio S, Stirling PC, Steidl C and Bally MB. Combined Use of Gene Expression Modeling and siRNA Screening Identifies Genes and Pathways Which Enhance the Activity of Cisplatin When Added at No Effect Levels to NonSmall Cell Lung Cancer Cells In Vitro. PloS one. 2016; 11:e0150675.

3. Weinshilboum RM, Otterness DM, Aksoy IA, Wood TC, Her C and Raftogianis RB. Sulfation and sulfotransferases 1: Sulfotransferase molecular biology: cDNAs and genes. FASEB journal. 1997; 11:3-14.

4. Alnouti $\mathrm{Y}$ and Klaassen CD. Tissue distribution and ontogeny of sulfotransferase enzymes in mice. Toxicological sciences. 2006; 93:242-255.

5. Gamage N, Barnett A, Hempel N, Duggleby RG, Windmill KF, Martin JL and McManus ME. Human sulfotransferases and their role in chemical metabolism. Toxicological sciences. 2006; 90:5-22.

6. Rosenthal E and Leustek T. A multifunctional Urechis caupo protein, PAPS synthetase, has both ATP sulfurylase and APS kinase activities. Gene. 1995; 165:243-248.

7. Klaassen CD and Boles JW. Sulfation and sulfotransferases 5: the importance of 3'-phosphoadenosine 5'-phosphosulfate (PAPS) in the regulation of sulfation. FASEB journal. 1997; 11:404-418.

8. Venkatachalam KV, Akita $\mathrm{H}$ and Strott CA. Molecular cloning, expression, and characterization of human bifunctional 3'-phosphoadenosine 5'-phosphosulfate synthase and its functional domains. The Journal of biological chemistry. 1998; 273:19311-19320.

9. Cherest H, Kerjan $\mathrm{P}$ and Surdinkerjan $\mathrm{Y}$. The Saccharomyces-Cerevisiae Met3 Gene - NucleotideSequence and Relationship of the 5' Noncoding Region to That of Met25. Mol Gen Genet. 1987; 210:307-313.

10. Foster BA, Thomas SM, Mahr JA, Renosto F, Patel HC and Segel IH. Cloning and Sequencing of Atp Sulfurylase from Penicillium-Chrysogenum - Identification of a Likely Allosteric Domain. Journal of Biological Chemistry. 1994; 269:19777-19786.

11. Leustek T, Murillo M and Cervantes M. Cloning of a CdnaEncoding Atp Sulfurylase from Arabidopsis-Thaliana by Functional Expression in Saccharomyces-Cerevisiae. Plant Physiol. 1994; 105:897-902.

12. Leyh TS. The physical biochemistry and molecular genetics of sulfate activation. Critical reviews in biochemistry and molecular biology. 1993; 28:515-542.

13. Leyh TS, Vogt TF and Suo Y. The DNA sequence of the sulfate activation locus from Escherichia coli K-12. The Journal of biological chemistry. 1992; 267:10405-10410.

14. Venkatachalam KV. Human 3'-phosphoadenosine 5'-phosphosulfate (PAPS) synthase: biochemistry, molecular biology and genetic deficiency. IUBMB life. 2003; 55:1-11.

15. Setya A, Murillo $M$ and Leustek T. Sulfate reduction in higher plants: molecular evidence for a novel 5 '-adenylylsulfate reductase. Proceedings of the National Academy of Sciences of the United States of America. 1996; 93:13383-13388.

16. Kopriva S, Buchert T, Fritz G, Suter M, Benda R, Schunemann V, Koprivova A, Schurmann P, Trautwein AX, Kroneck PM and Brunold C. The presence of an ironsulfur cluster in adenosine 5'-phosphosulfate reductase separates organisms utilizing adenosine 5'-phosphosulfate and phosphoadenosine 5'-phosphosulfate for sulfate assimilation. The Journal of biological chemistry. 2002; 277:21786-21791.

17. $\mathrm{Xu} \mathrm{ZH}$, Otterness DM, Freimuth RR, Carlini EJ, Wood TC, Mitchell S, Moon E, Kim UJ, Xu JP, Siciliano MJ and Weinshilboum RM. Human 3'-phosphoadenosine 5'-phosphosulfate synthetase 1 (PAPSS1) and PAPSS2: gene cloning, characterization and chromosomal localization. Biochemical and biophysical research communications. 2000; 268:437-444.

18. Besset S, Vincourt JB, Amalric F and Girard JP. Nuclear localization of PAPS synthetase 1: a sulfate activation pathway in the nucleus of eukaryotic cells. FASEB journal. 2000; 14:345-354.

19. Schroder E, Gebel L, Eremeev AA, Morgner J, Grum D, Knauer SK, Bayer P and Mueller JW. Human PAPS synthase isoforms are dynamically regulated enzymes with 
access to nucleus and cytoplasm. PloS one. 2012; 7:e29559.

20. $\mathrm{Xu} \mathrm{ZH}$, Thomae BA, Eckloff BW, Wieben ED and Weinshilboum RM. Pharmacogenetics of human 3'-phosphoadenosine 5'-phosphosulfate synthetase 1 (PAPSS1): gene resequencing, sequence variation, and functional genomics. Biochemical pharmacology. 2003; 65:1787-1796.

21. Gillet JP and Gottesman MM. Mechanisms of multidrug resistance in cancer. Methods Mol Biol. 2010; 596:47-76.

22. Negishi M, Pedersen LG, Petrotchenko E, Shevtsov S, Gorokhov A, Kakuta Y and Pedersen LC. Structure and function of sulfotransferases. Archives of biochemistry and biophysics. 2001; 390:149-157.

23. Falany CN. Enzymology of human cytosolic sulfotransferases. FASEB journal. 1997; 11:206-216.

24. Falany CN. Sulfation and sulfotransferases. Introduction: changing view of sulfation and the cytosolic sulfotransferases. FASEB journal. 1997; 11:1-2.

25. Rondini EA, Fang H, Runge-Morris M and Kocarek TA. Regulation of human cytosolic sulfotransferases $1 \mathrm{C} 2$ and 1C3 by nuclear signaling pathways in LS180 colorectal adenocarcinoma cells. Drug metabolism and disposition: the biological fate of chemicals. 2014; 42:361-368.

26. Tibbs ZE, Rohn-Glowacki KJ, Crittenden F, Guidry AL and Falany CN. Structural plasticity in the human cytosolic sulfotransferase dimer and its role in substrate selectivity and catalysis. Drug metabolism and pharmacokinetics. 2015; 30:3-20.

27. Dereeper A, Audic S, Claverie JM and Blanc G. BLASTEXPLORER helps you building datasets for phylogenetic analysis. BMC evolutionary biology. 2010; 10:8.

28. Edgar RC. MUSCLE: multiple sequence alignment with high accuracy and high throughput. Nucleic acids research. 2004; 32:1792-1797.

29. Dereeper A, Guignon V, Blanc G, Audic S, Buffet S, Chevenet F, Dufayard JF, Guindon S, Lefort V, Lescot M, Claverie JM and Gascuel O. Phylogeny.fr: robust phylogenetic analysis for the non-specialist. Nucleic acids research. 2008; 36:W465-469.

30. Castresana J. Selection of conserved blocks from multiple alignments for their use in phylogenetic analysis. Mol Biol Evol. 2000; 17:540-552.

31. Guindon S and Gascuel O. A simple, fast, and accurate algorithm to estimate large phylogenies by maximum likelihood. Syst Biol. 2003; 52:696-704.

32. Anisimova M and Gascuel O. Approximate likelihood-ratio test for branches: A fast, accurate, and powerful alternative. Syst Biol. 2006; 55:539-552.

33. Chevenet F, Brun C, Banuls AL, Jacq B and Christen R. TreeDyn: towards dynamic graphics and annotations for analyses of trees. BMC bioinformatics. 2006; 7.

34. Duniec-Dmuchowski Z, Rondini EA, Tibbs ZE, Falany $\mathrm{CN}$, Runge-Morris $\mathrm{M}$ and Kocarek TA. Expression of the orphan cytosolic sulfotransferase SULT1C3 in human intestine: characterization of the transcript variant and implications for function. Drug metabolism and disposition: the biological fate of chemicals. 2014; 42:352-360.

35. Freimuth RR, Wiepert M, Chute CG, Wieben ED and Weinshilboum RM. Human cytosolic sulfotransferase database mining: identification of seven novel genes and pseudogenes. The pharmacogenomics journal. 2003; 4:5465.

36. Glatt H. Sulfotransferases in the bioactivation of xenobiotics. Chemico-biological interactions. 2000; 129:141-170.

37. Coughtrie MW. Sulfation through the looking glass - recent advances in sulfotransferase research for the curious. The pharmacogenomics journal. 2002; 2:297-308.

38. Riches Z, Stanley EL, Bloomer JC and Coughtrie MW. Quantitative evaluation of the expression and activity of five major sulfotransferases (SULTs) in human tissues: the SULT "pie". Drug metabolism and disposition: the biological fate of chemicals. 2009; 37:2255-2261.

39. Coughtrie MW. Function and organization of the human cytosolic sulfotransferase (SULT) family. Chemicobiological interactions. 2016.

40. Falany CN. (2005). Human Cytosolic Sulfotransferases. In: Las LH, ed. Drug Metabolism and Transport: Molecular Methods and Mechanisms. (Totowa, NJ: Humana Press), pp. 341-378.

41. Hempel N, Negishi M and McManus ME. (2005). Human SULT1A Genes: Cloning and Activity Assays of the SULT1A Promoters. Methods in Enzymology: Academic Press), pp. 147-165.

42. Lindsay J, Wang LL, Li Y and Zhou SF. Structure, function and polymorphism of human cytosolic sulfotransferases. Current drug metabolism. 2008; 9:99-105.

43. Falany CN, Wheeler J, Oh TS and Falany JL. Steroid sulfation by expressed human cytosolic sulfotransferases. The Journal of steroid biochemistry and molecular biology. 1994; 48:369-375.

44. Cook I, Wang T, Almo SC, Kim J, Falany CN and Leyh TS. The Gate That Governs Sulfotransferase Selectivity. Biochemistry. 2013; 52:415-424.

45. Glatt H. Sulfation and sulfotransferases 4: bioactivation of mutagens via sulfation. FASEB journal. 1997; 11:314-321.

46. Coughtrie MW, Sharp S, Maxwell K and Innes NP. Biology and function of the reversible sulfation pathway catalysed by human sulfotransferases and sulfatases. Chemicobiological interactions. 1998; 109:3-27.

47. Buhl AE, Waldon DJ, Baker CA and Johnson GA. Minoxidil sulfate is the active metabolite that stimulates hair follicles. The Journal of investigative dermatology. 1990; 95:553-557.

48. Meisheri KD, Cipkus LA and Taylor CJ. Mechanism of action of minoxidil sulfate-induced vasodilation: a role for 
increased $\mathrm{K}+$ permeability. The Journal of pharmacology and experimental therapeutics. 1988; 245:751-760.

49. Niehrs C, Beisswanger $\mathrm{R}$ and Huttner WB. Protein tyrosine sulfation, 1993 - an update. Chemico-biological interactions. 1994; 92:257-271.

50. Huttner WB. Protein tyrosine sulfation. Trends in Biochemical Sciences. 1987; 12:361-363.

51. Kehoe JW and Bertozzi CR. Tyrosine sulfation: a modulator of extracellular protein-protein interactions. Chemistry \& biology. 2000; 7:R57-61.

52. Baeuerle PA and Huttner WB. Tyrosine sulfation is a transGolgi-specific protein modification. The Journal of cell biology. 1987; 105:2655-2664.

53. Ozeran JD, Westley J and Schwartz NB. Identification and partial purification of PAPS translocase. Biochemistry. 1996; 35:3695-3703.

54. Ozeran JD, Westley J and Schwartz NB. Kinetics of PAPS translocase: evidence for an antiport mechanism. Biochemistry. 1996; 35:3685-3694.

55. Brand SJ, Andersen BN and Rehfeld JF. Complete tyrosine$\mathrm{O}$-sulphation of gastrin in neonatal rat pancreas. Nature. 1984; 309:456-458.

56. Pouyani T and Seed B. PSGL-1 recognition of P-selectin is controlled by a tyrosine sulfation consensus at the PSGL-1 amino terminus. Cell. 1995; 83:333-343.

57. Sako D, Comess KM, Barone KM, Camphausen RT, Cumming DA and Shaw GD. A sulfated peptide segment at the amino terminus of PSGL-1 is critical for P-selectin binding. Cell. 1995; 83:323-331.

58. Wilkins PP, Moore KL, McEver RP and Cummings RD. Tyrosine sulfation of P-selectin glycoprotein ligand-1 is required for high affinity binding to P-selectin. The Journal of biological chemistry. 1995; 270:22677-22680.

59. Farzan M, Mirzabekov T, Kolchinsky P, Wyatt R, Cayabyab M, Gerard NP, Gerard C, Sodroski J and Choe H. Tyrosine sulfation of the amino terminus of CCR 5 facilitates HIV-1 entry. Cell. 1999; 96:667-676.

60. Esko JD and Lindahl U. Molecular diversity of heparan sulfate. The Journal of clinical investigation. 2001; 108:169-173.

61. Lindahl U, Kusche-Gullberg M and Kjellen L. Regulated diversity of heparan sulfate. The Journal of biological chemistry. 1998; 273:24979-24982.

62. Rosenberg RD, Shworak NW, Liu J, Schwartz JJ and Zhang L. Heparan sulfate proteoglycans of the cardiovascular system. Specific structures emerge but how is synthesis regulated? The Journal of clinical investigation. 1997; 99:2062-2070.

63. Salmivirta M, Lidholt K and Lindahl U. Heparan sulfate: a piece of information. FASEB journal. 1996; 10:1270-1279.

64. Lindahl U, Lidholt K, Spillmann D and Kjellen L. More to "heparin" than anticoagulation. Thrombosis research. 1994; 75:1-32.
65. Bernfield M, Gotte M, Park PW, Reizes O, Fitzgerald ML, Lincecum $J$ and Zako M. Functions of cell surface heparan sulfate proteoglycans. Annual review of biochemistry. 1999; 68:729-777.

66. Gallagher JT, Lyon M and Steward WP. Structure and function of heparan sulphate proteoglycans. The Biochemical journal. 1986; 236:313-325.

67. Dreyfuss JL, Regatieri CV, Jarrouge TR, Cavalheiro RP, Sampaio LO and Nader HB. Heparan sulfate proteoglycans: structure, protein interactions and cell signaling. Anais da Academia Brasileira de Ciencias. 2009; 81:409-429.

68. Sarrazin S, Lamanna WC and Esko JD. Heparan sulfate proteoglycans. Cold Spring Harbor perspectives in biology. $2011 ; 3$.

69. Superti-Furga A. A defect in the metabolic activation of sulfate in a patient with achondrogenesis type IB. American journal of human genetics. 1994; 55:1137-1145.

70. Karniski LP. Mutations in the diastrophic dysplasia sulfate transporter (DTDST) gene: correlation between sulfate transport activity and chondrodysplasia phenotype. Human molecular genetics. 2001; 10:1485-1490.

71. Rossi A, Bonaventure J, Delezoide AL, Cetta G and SupertiFurga A. Undersulfation of proteoglycans synthesized by chondrocytes from a patient with achondrogenesis type 1B homozygous for an L483P substitution in the diastrophic dysplasia sulfate transporter. The Journal of biological chemistry. 1996; 271:18456-18464.

72. Miyake N, Elcioglu NH, Iida A, Isguven P, Dai J, Murakami N, Takamura K, Cho TJ, Kim OH, Hasegawa T, Nagai T, Ohashi H, Nishimura G, Matsumoto N and Ikegawa S. PAPSS2 mutations cause autosomal recessive brachyolmia. Journal of medical genetics. 2012; 49:533-538.

73. Ludeman JP and Stone MJ. The structural role of receptor tyrosine sulfation in chemokine recognition. British journal of pharmacology. 2014; 171:1167-1179.

74. Westmuckett AD, Hoffhines AJ, Borghei A and Moore KL. Early postnatal pulmonary failure and primary hypothyroidism in mice with combined TPST-1 and TPST2 deficiency. General and comparative endocrinology. 2008; 156:145-153.

75. Sasaki N, Hosoda Y, Nagata A, Ding M, Cheng JM, Miyamoto T, Okano S, Asano A, Miyoshi I and Agui T. A mutation in Tpst 2 encoding tyrosylprotein sulfotransferase causes dwarfism associated with hypothyroidism. Mol Endocrinol. 2007; 21:1713-1721.

76. Liu J, Louie S, Hsu W, Yu KM, Nicholas HB, Jr. and Rosenquist GL. Tyrosine sulfation is prevalent in human chemokine receptors important in lung disease. American journal of respiratory cell and molecular biology. 2008; 38:738-743.

77. Zhu JZ, Millard CJ, Ludeman JP, Simpson LS, Clayton DJ, Payne RJ, Widlanski TS and Stone MJ. Tyrosine sulfation influences the chemokine binding selectivity of peptides derived from chemokine receptor CCR3. Biochemistry. 
2011; 50:1524-1534.

78. Schumacher A, Liebers U, John M, Gerl V, Meyer M, Witt $\mathrm{C}$ and Wolff G. P-selectin glycoprotein ligand-1 (PSGL1) is up-regulated on leucocytes from patients with chronic obstructive pulmonary disease. Clinical and experimental immunology. 2005; 142:370-376.

79. Bruce JW, Ahlquist P and Young JA. The host cell sulfonation pathway contributes to retroviral infection at a step coincident with provirus establishment. PLoS pathogens. 2008; 4:e1000207.

80. Liu J and Thorp SC. Cell surface heparan sulfate and its roles in assisting viral infections. Medicinal research reviews. 2002; 22:1-25.

81. Herold BC, WuDunn D, Soltys $\mathrm{N}$ and Spear PG. Glycoprotein $\mathrm{C}$ of herpes simplex virus type 1 plays a principal role in the adsorption of virus to cells and in infectivity. Journal of virology. 1991; 65:1090-1098.

82. Shukla D, Liu J, Blaiklock P, Shworak NW, Bai X, Esko JD, Cohen GH, Eisenberg RJ, Rosenberg RD and Spear PG. A novel role for 3-O-sulfated heparan sulfate in herpes simplex virus 1 entry. Cell. 1999; 99:13-22.

83. WuDunn D and Spear PG. Initial interaction of herpes simplex virus with cells is binding to heparan sulfate. Journal of virology. 1989; 63:52-58.

84. Ugolini S, Mondor I and Sattentau QJ. HIV-1 attachment: another look. Trends in microbiology. 1999; 7:144-149.

85. Gallay P. Syndecans and HIV-1 pathogenesis. Microbes and infection / Institut Pasteur. 2004; 6:617-622.

86. Feng Y, Broder CC, Kennedy PE and Berger EA. HIV1 entry cofactor: functional cDNA cloning of a seventransmembrane, G protein-coupled receptor. Science. 1996; 272:872-877.

87. Gatignol A and Jeang KT. Tat as a transcriptional activator and a potential therapeutic target for HIV-1. Adv Pharmacol. 2000; 48:209-227.

88. Tyagi $M$, Rusnati $M$, Presta $M$ and Giacca $M$. Internalization of HIV-1 tat requires cell surface heparan sulfate proteoglycans. The Journal of biological chemistry. 2001; 276:3254-3261.

89. Hemmerich S, Verdugo D and Rath VL. Strategies for drug discovery by targeting sulfation pathways. Drug discovery today. 2004; 9:967-975.

90. Hirata H, Hinoda Y, Okayama N, Suehiro Y, Kawamoto K, Kikuno N, Rabban JT, Chen LM and Dahiya R. CYP1A1, SULT1A1, and SULT1E1 polymorphisms are risk factors for endometrial cancer susceptibility. Cancer. 2008; 112:1964-1973.

91. Rebbeck TR, Troxel AB, Wang Y, Walker AH, Panossian S, Gallagher S, Shatalova EG, Blanchard R, Bunin G, DeMichele A, Rubin SC, Baumgarten M, Berlin M, Schinnar R, Berlin JA and Strom BL. Estrogen sulfation genes, hormone replacement therapy, and endometrial cancer risk. Journal of the National Cancer Institute. 2006; 98:1311-1320.
92. Choi JY, Lee KM, Park SK, Noh DY, Ahn SH, Chung HW, Han W, Kim JS, Shin SG, Jang IJ, Yoo KY, Hirvonen A and Kang D. Genetic polymorphisms of SULT1A1 and SULT1E1 and the risk and survival of breast cancer. Cancer epidemiology, biomarkers \& prevention : a publication of the American Association for Cancer Research, cosponsored by the American Society of Preventive Oncology. 2005; 14:1090-1095.

93. Falany JL and Falany CN. Expression of cytosolic sulfotransferases in normal mammary epithelial cells and breast cancer cell lines. Cancer research. 1996; 56:15511555.

94. Xu Y, Liu X, Guo F, Ning Y, Zhi X, Wang X, Chen S, Yin L and Li X. Effect of estrogen sulfation by SULT1E1 and PAPSS on the development of estrogen-dependent cancers. Cancer science. 2012; 103:1000-1009.

95. Jiang Y, Zhou L, Yan T, Shen Z, Shao Z and Lu J. Association of sulfotransferase SULT1A1 with breast cancer risk: a meta-analysis of case-control studies with subgroups of ethnic and menopausal statue. Journal of Experimental \& Clinical Cancer Research. 2010; 29:1-10.

96. Han D-F, Zhou X, Hu M-B, Xie W, Mao Z-f, Chen D-e, Liu $\mathrm{F}$ and Zheng F. Polymorphisms of estrogen-metabolizing genes and breast cancer risk: a multigenic study. Chin Med J (Engl). 2005; 118:1507-1516.

97. Nowell S, Sweeney C, Winters M, Stone A, Lang NP, Hutchins LF, Kadlubar FF and Ambrosone CB. Association between sulfotransferase 1A1 genotype and survival of breast cancer patients receiving tamoxifen therapy. Journal of the National Cancer Institute. 2002; 94:1635-1640.

98. Wegman P, Vainikka L, Stål O, Nordenskjöld B, Skoog L, Rutqvist L-E and Wingren S. Genotype of metabolic enzymes and the benefit of tamoxifen in postmenopausal breast cancer patients. Breast Cancer Research. 2005; 7:1-7.

99. Nowell S and Falany CN. Pharmacogenetics of human cytosolic sulfotransferases. Oncogene. 0000; 25:1673-1678.

100. Mikhailova ON, Gulyaeva LF, Prudnikov AV, Gerasimov AV and Krasilnikov SE. Estrogen-metabolizing gene polymorphisms in the assessment of female hormonedependent cancer risk. The pharmacogenomics journal. 2006; 6:189-193.

101. O’Mara TA, Ferguson K, Fahey P, Marquart L, Yang HP, Lissowska J, Chanock S, Garcia-Closas M, Thompson DJ, Healey CS, Dunning AM, Easton DF, Webb PM and Spurdle AB. CHEK2, MGMT, SULT1E1 and SULT1A1 polymorphisms and endometrial cancer risk. Twin research and human genetics. 2011; 14:328-332.

102. Hirata H, Hinoda Y, Okayama N, Suehiro Y, Kawamoto K, Kikuno N, Rabban JT, Chen LM and Dahiya R. CYP1A1, SULT1A1, and SULT1E1 polymorphisms are risk factors for endometrial cancer susceptibility. Cancer. 2008; 112:1964-1973.

103. Gulyaeva LF, Mikhailova ON, PustyInyak VO, Kim IVt, Gerasimov AV, Krasilnikov SE, Filipenko ML and 
Pechkovsky EV. Comparative analysis of SNP in estrogenmetabolizing enzymes for ovarian, endometrial, and breast cancers in Novosibirsk, Russia. Advances in experimental medicine and biology. 2008; 617:359-366.

104. Liang G, Miao X, Zhou Y, Tan W and Lin D. A functional polymorphism in the SULT1A1 gene (G638A) is associated with risk of lung cancer in relation to tobacco smoking. Carcinogenesis. 2004; 25:773-778.

105. Wang YF, Spitz MR, Tsou AMH, Zhang KR, Makan N and $\mathrm{Wu}$ XF. Sulfotransferase (SULT) 1A1 polymorphism as a predisposition factor for lung cancer: a case-control analysis. Lung Cancer-J Iaslc. 2002; 35:137-142.

106. Pachouri SS, Sobti RC, Kaur P, Singh J and Gupta SK. Impact of polymorphism in sulfotransferase gene on the risk of lung cancer. Cancer Genet Cytogen. 2006; 171:39-43.

107. Zheng LZ, Wang YF, Schabath MB, Grossman HB and Wu XF. Sulfotransferase 1A1 (SULT1A1) polymorphism and bladder cancer risk: a case-control study. Cancer Lett. 2003; 202:61-69.

108. Hung RJ, Boffetta P, Brennan P, Malaveille C, Hautefeuille A, Donato F, Gelatti U, Spaliviero M, Placidi D, Carta A, di Carlo AS and Porru S. GST, NAT, SULT1A1, CYP1B1 genetic polymorphisms, interactions with environmental exposures and bladder cancer risk in a high-risk population. Int J Cancer. 2004; 110:598-604.

109. Roupret M, Cancel-Tassin G, Comperat E, Fromont G, Sibony M, Molinie V, Allory Y, Triau S, Champigneulle J, Gaffory C, Larre S, de la Taille A, Richard F, Hamdy FC and Cussenot O. Phenol sulfotransferase SULT1A1*2 allele and enhanced risk of upper urinary tract urothelial cell carcinoma. Cancer Epidem Biomar. 2007; 16:2500-2503.

110. Boccia S, Cadoni G, La Torre G, Arzani D, Volante M, Cattel C, Gianfagna F, Paludetti G, Almadori G and Ricciardi G. A case-control study investigating the role of sulfotransferase 1A1 polymorphism in head and neck cancer. J Cancer Res Clin. 2006; 132:466-472.

111. Boccia S, Persiani R, La Torre G, Rausei S, Arzani D, Gianfagna F, Romano-Spica V, D’Ugo D and Ricciardi G. Sulfotransferase $1 \mathrm{~A} 1$ polymorphism and gastric cancer risk: a pilot case-control study. Cancer Lett. 2005; 229:235-243.

112. Lilla C, Risch A, Verla-Tebit E, Hoffmeister M, Brenner H and Chang-Claude J. SULT1A1 genotype and susceptibility to colorectal cancer. Int J Cancer. 2007; 120:201-206.

113. Asimakopoulou AP, Theocharis AD, Tzanakakis GN and Karamanos NK. The biological role of chondroitin sulfate in cancer and chondroitin-based anticancer agents. In Vivo. 2008; 22:385-389.

114. Martins JR, Gadelha ME, Fonseca SM, Sampaio LO, De LPPA, Dietrich CP and Nader HB. Patients with head and neck tumors excrete a chondroitin sulfate with a low degree of sulfation: a new tool for diagnosis and follow-up of cancer therapy. Otolaryngology — head and neck surgery. 2000; 122:115-118.
115. Sampaio LO, Dietrich CP and Filho OG. Changes in sulfated mucopolysaccharide composition of mammalian tissues during growth and in cancer tissues. Biochimica et biophysica acta. 1977; 498:123-131.

116. Angello JC, Danielson KG, Anderson LW and Hosick HL. Glycosaminoglycan synthesis by subpopulations of epithelial cells from a mammary adenocarcinoma. Cancer research. 1982; 42:2207-2210.

117. Skandalis SS, Labropoulou VT, Ravazoula P, LikakiKaratza E, Dobra K, Kalofonos HP, Karamanos NK and Theocharis AD. Versican but not decorin accumulation is related to malignancy in mammographically detected high density and malignant-appearing microcalcifications in nonpalpable breast carcinomas. Bmc Cancer. 2011; 11.

118. Wegrowski Y and Maquart FX. Chondroitin sulfate proteoglycans in tumor progression. Adv Pharmacol. 2006; 53:297-321.

119. Cooney CA, Jousheghany F, Yao-Borengasser A, Phanavanh B, Gomes T, Kieber-Emmons AM, Siegel ER, Suva LJ, Ferrone S, Kieber-Emmons T and MonzaviKarbassi B. Chondroitin sulfates play a major role in breast cancer metastasis: a role for CSPG4 and CHST11 gene expression in forming surface P-selectin ligands in aggressive breast cancer cells. Breast cancer research. 2011; 13:R58.

120. Sanderson RD, Yang Y, Suva LJ and Kelly T. Heparan sulfate proteoglycans and heparanase-partners in osteolytic tumor growth and metastasis. Matrix Biol. 2004; 23:341-352.

121. Wei Poh Z, Heng Gan C, Lee EJ, Guo S, Yip GW and Lam Y. Divergent Synthesis of Chondroitin Sulfate Disaccharides and Identification of Sulfate Motifs that Inhibit Triple Negative Breast Cancer. Scientific Reports. 2015; 5:14355.

122. Sasisekharan R, Shriver Z, Venkataraman G and Narayanasami U. Roles of heparan-sulphate glycosaminoglycans in cancer. Nature reviews Cancer. 2002; 2:521-528.

123. Xiang YY, Ladeda V and Filmus J. Glypican-3 expression is silenced in human breast cancer. Oncogene. 2001; 20:7408-7412.

124. Lin H, Huber R, Schlessinger D and Morin PJ. Frequent silencing of the GPC3 gene in ovarian cancer cell lines. Cancer research. 1999; 59:807-810.

125. Murthy SS, Shen T, De Rienzo A, Lee WC, Ferriola PC, Jhanwar SC, Mossman BT, Filmus J and Testa JR. Expression of GPC3, an X-linked recessive overgrowth gene, is silenced in malignant mesothelioma. Oncogene. 2000; 19:410-416.

126. Lemjabbar-Alaoui H, van Zante A, Singer MS, Xue Q, Wang YQ, Tsay D, He B, Jablons DM and Rosen SD. Sulf2, a heparan sulfate endosulfatase, promotes human lung carcinogenesis. Oncogene. 2010; 29:635-646. 
127. Morimoto-Tomita M, Uchimura K, Bistrup A, Lum DH, Egeblad M, Boudreau N, Werb Z and Rosen SD. Sulf-2, a proangiogenic heparan sulfate endosulfatase, is upregulated in breast cancer. Neoplasia. 2005; 7:1001-1010.

128. Takebe N, Harris PJ, Warren RQ and Ivy SP. Targeting cancer stem cells by inhibiting Wnt, Notch, and Hedgehog pathways. Nature reviews Clinical oncology. 2011; 8:97106.

129. Shute JK, Solic N, Shimizu J, McConnell W, Redington AE and Howarth PH. Epithelial expression and release of FGF2 from heparan sulphate binding sites in bronchial tissue in asthma. Thorax. 2004; 59:557-562.

130. Iozzo RV and San Antonio JD. Heparan sulfate proteoglycans: heavy hitters in the angiogenesis arena. The Journal of clinical investigation. 2001; 108:349-355.

131. Cole CL, Rushton G, Jayson GC and Avizienyte E. Ovarian Cancer Cell Heparan Sulfate 6-O-Sulfotransferases Regulate an Angiogenic Program Induced by Heparinbinding Epidermal Growth Factor (EGF)-like Growth Factor/EGF Receptor Signaling. Journal of Biological Chemistry. 2014; 289:10488-10501.

132. Mao X, Gauche C, Coughtrie MWH, Bui C, Gulberti S, Merhi-Soussi F, Ramalanjaona N, Bertin-Jung I, Diot A, Dumas D, De Freitas Caires N, Thompson AM, Bourdon JC, Ouzzine M and Fournel-Gigleux S. The heparan sulfate sulfotransferase 3-OST3A (HS3ST3A) is a novel tumor regulator and a prognostic marker in breast cancer. Oncogene. 2016.

133. Vijaya Kumar A, Salem Gassar E, Spillmann D, Stock C, Sen Y-P, Zhang T, Van Kuppevelt TH, Hülsewig C, Koszlowski EO, Pavao MSG, Ibrahim SA, Poeter M, Rescher U, et al. HS3ST2 modulates breast cancer cell invasiveness via MAP kinase- and Tcf4 (Tcf712)-dependent regulation of protease and cadherin expression. Int J Cancer. 2014; 135:2579-2592.

134. Jung SH, Lee HC, Yu DM, Kim BC, Park SM, Lee YS, Park HJ, Ko YG and Lee JS. Heparan sulfation is essential for the prevention of cellular senescence. Cell Death Differ. 2016; 23:417-429.

135. Sanderson RD. Heparan sulfate proteoglycans in invasion and metastasis. Seminars in cell \& developmental biology. 2001; 12:89-98.

136. Hulett MD, Freeman C, Hamdorf BJ, Baker RT, Harris $\mathrm{MJ}$ and Parish CR. Cloning of mammalian heparanase, an important enzyme in tumor invasion and metastasis. Nature medicine. 1999; 5:803-809.

137. Vlodavsky I, Friedmann Y, Elkin M, Aingorn H, Atzmon R, Ishai-Michaeli R, Bitan M, Pappo O, Peretz T, Michal I, Spector L and Pecker I. Mammalian heparanase: gene cloning, expression and function in tumor progression and metastasis. Nature medicine. 1999; 5:793-802.

138. Liu D, Shriver Z, Qi Y, Venkataraman G and Sasisekharan R. Dynamic regulation of tumor growth and metastasis by heparan sulfate glycosaminoglycans. Seminars in thrombosis and hemostasis. 2002; 28:67-78.

139. Bar-Ner M, Kramer MD, Schirrmacher V, Ishai-Michaeli R, Fuks $\mathrm{Z}$ and Vlodavsky I. Sequential degradation of heparan sulfate in the subendothelial extracellular matrix by highly metastatic lymphoma cells. Int J Cancer. 1985; 35:483-491.

140. Day RM, Hao X, Ilyas M, Daszak P, Talbot IC and Forbes A. Changes in the expression of syndecan- 1 in the colorectal adenoma-carcinoma sequence. Virchows Archiv. 1999; 434:121-125.

141. Kumar-Singh S, Jacobs W, Dhaene K, Weyn B, Bogers J, Weyler J and Van Marck E. Syndecan-1 expression in malignant mesothelioma: correlation with cell differentiation, WT1 expression, and clinical outcome. The Journal of pathology. 1998; 186:300-305.

142. Nackaerts K, Verbeken E, Deneffe G, Vanderschueren B, Demedts $\mathrm{M}$ and David G. Heparan sulfate proteoglycan expression in human lung-cancer cells. Int J Cancer. 1997; 74:335-345.

143. Matsumoto A, Ono M, Fujimoto Y, Gallo RL, Bernfield M and Kohgo Y. Reduced expression of syndecan-1 in human hepatocellular carcinoma with high metastatic potential. Int J Cancer. 1997; 74:482-491.

144. Inki P, Joensuu H, Grenman R, Klemi P and Jalkanen M. Association between syndecan-1 expression and clinical outcome in squamous cell carcinoma of the head and neck. British journal of cancer. 1994; 70:319-323.

145. Heidari-Hamedani G, Vivès RR, Seffouh A, Afratis NA, Oosterhof A, van Kuppevelt TH, Karamanos NK, Metintas M, Hjerpe A, Dobra K and Szatmári T. Syndecan-1 alters heparan sulfate composition and signaling pathways in malignant mesothelioma. Cell Signal. 2015; 27:2054-2067.

146. Martinez P, Vergoten G, Colomb F, Bobowski M, Steenackers A, Carpentier M, Allain F, Delannoy P and Julien S. Over-sulfated glycosaminoglycans are alternative selectin ligands: insights into molecular interactions and possible role in breast cancer metastasis. Clinical \& experimental metastasis. 2013; 30:919-931.

147. Savore C, Zhang C, Muir C, Liu R, Wyrwa J, Shu J, Zhau HE, Chung LW, Carson DD and Farach-Carson MC. Perlecan knockdown in metastatic prostate cancer cells reduces heparin-binding growth factor responses in vitro and tumor growth in vivo. Clinical \& experimental metastasis. 2005; 22:377-390.

148. Adatia R, Albini A, Carlone S, Giunciuglio D, Benelli R, Santi L and Noonan DM. Suppression of invasive behavior of melanoma cells by stable expression of anti-sense perlecan cDNA. Annals of oncology. 1997; 8:1257-1261.

149. Robertson NP, Starkey JR, Hamner S and Meadows GG. Tumor cell invasion of three-dimensional matrices of defined composition: evidence for a specific role for heparan sulfate in rodent cell lines. Cancer research. 1989; 49:1816-1823.

150. Liebersbach BF and Sanderson RD. Expression of syndecan-1 inhibits cell invasion into type I collagen. The 
Journal of biological chemistry. 1994; 269:20013-20019.

151. Bitan M, Mohsen M, Levi E, Wygoda MR, Miao HQ, Lider O, Svahn CM, Ekre HP, Ishai-Michaeli R, Bar-Shavit R and et al. Structural requirements for inhibition of melanoma lung colonization by heparanase inhibiting species of heparin. Israel journal of medical sciences. 1995; 31:106118.

152. Tovari J, Paku S, Raso E, Pogany G, Kovalszky I, Ladanyi A, Lapis K and Timar J. Role of sinusoidal heparan sulfate proteoglycan in liver metastasis formation. Int $\mathrm{J}$ Cancer. 1997; 71:825-831.

153. Engelberg H. Actions of heparin that may affect the malignant process. Cancer. 1999; 85:257-272.

154. Lever $\mathrm{R}$ and Page CP. Novel drug development opportunities for heparin. Nature reviews Drug discovery. 2002; 1:140-148.

155. Smorenburg SM and Van Noorden CJ. The complex effects of heparins on cancer progression and metastasis in experimental studies. Pharmacological reviews. 2001; 53:93-105.

156. Yip GW, Smollich M and Gotte M. Therapeutic value of glycosaminoglycans in cancer. Molecular cancer therapeutics. 2006; 5:2139-2148.
157. Shih WL, Yu MW, Chen PJ, Wu TW, Lin CL, Liu CJ, Lin SM, Tai DI, Lee SD and Liaw YF. Evidence for association with hepatocellular carcinoma at the PAPSS1 locus on chromosome 4q25 in a family-based study. European journal of human genetics. 2009; 17:1250-1259.

158. Grum D, van den Boom J, Neumann D, Matena A, Link NM and Mueller JW. A heterodimer of human 3'-phosphoadenosine-5'-phosphosulphate (PAPS) synthases is a new sulphate activating complex. Biochemical and biophysical research communications. 2010; 395:420-425.

159. van den Boom J, Heider D, Martin SR, Pastore A and Mueller JW. 3'-Phosphoadenosine 5'-phosphosulfate (PAPS) synthases, naturally fragile enzymes specifically stabilized by nucleotide binding. The Journal of biological chemistry. 2012; 287:17645-17655.

160. Monigatti F, Gasteiger E, Bairoch A and Jung E. The Sulfinator: predicting tyrosine sulfation sites in protein sequences. Bioinformatics. 2002; 18:769-770.

161. Mehlen P and Puisieux A. Metastasis: a question of life or death. Nature reviews Cancer. 2006; 6:449-458. 